ACCEPTED MANUSCRIPT

\title{
Characterisation of wear areas on UHMWPE total knee replacement prostheses through study of their areal surface topographical parameters
}

To cite this article before publication: Matthew Holland et al 2018 Surf. Topogr.: Metrol. Prop. in press https://doi.org/10.1088/2051-672X/aac071

\section{Manuscript version: Accepted Manuscript}

Accepted Manuscript is "the version of the article accepted for publication including all changes made as a result of the peer review process, and which may also include the addition to the article by IOP Publishing of a header, an article ID, a cover sheet and/or an 'Accepted Manuscript' watermark, but excluding any other editing, typesetting or other changes made by IOP Publishing and/or its licensors"

This Accepted Manuscript is @ 2018 IOP Publishing Ltd.

During the embargo period (the 12 month period from the publication of the Version of Record of this article), the Accepted Manuscript is fully protected by copyright and cannot be reused or reposted elsewhere.

As the Version of Record of this article is going to be / has been published on a subscription basis, this Accepted Manuscript is available for reuse under a CC BY-NC-ND 3.0 licence after the 12 month embargo period.

After the embargo period, everyone is permitted to use copy and redistribute this article for non-commercial purposes only, provided that they adhere to all the terms of the licence https://creativecommons.org/licences/by-nc-nd/3.0

Although reasonable endeavours have been taken to obtain all necessary permissions from third parties to include their copyrighted content within this article, their full citation and copyright line may not be present in this Accepted Manuscript version. Before using any content from this article, please refer to the Version of Record on IOPscience once published for full citation and copyright details, as permissions will likely be required. All third party content is fully copyright protected, unless specifically stated otherwise in the figure caption in the Version of Record.

View the article online for updates and enhancements. 


\title{
Characterisation of wear areas on UHMWPE Total Knee Replacement Prostheses through study of their areal surface topographical parameters
}

\author{
Holland, Matthew'; Fleming, Leigh'; Walton, Karl' ${ }^{1}$; Cerquiglini, Arianna²; \\ Hothi, Harry²; Hart, Alister²; Skinner, John²; Bills, Paul ${ }^{1}$. \\ ${ }^{1}$ EPSRC Future Metrology Hub, University of Huddersfield, UK \\ ${ }^{2}$ London Implant Retrieval Centre, University College London, UK \\ E-mail: matthew.holland@hud.ac.uk
}

\begin{abstract}
Total knee replacement is one of the most common elective surgeries in the world, and presents a number of challenges related to the wear of ultra-high molecular weight polyethylene (UHMWPE). This paper prese

nts an analysis of the surface topographical properties of the worn and unworn condylar surfaces on a small cohort of both wear simulated and retrieved prostheses of varying designs. A number of measurement points were taken on each prostheses in a mixture of worn and unworn areas through the use of focus-variation microscopy (FVM), a non-contact method of surface measurement. Surface areal parameters were extracted from this data to analyse and search for patterns within the data. It was found that in general, worn implant surfaces appear to show smoother, less peak dominated surfaces than unworn area. It was also found that wear simulated and retrieved implants display similar characteristics of surface topography. In addition, variation was noted between different designs of TKR device, with posterior stabilised designs found to be peak dominated and cruciate retaining type implants being valley dominated.
\end{abstract}

\subsection{Introduction}

The wear of ultra-high molecular weight polyethylene (UHMWPE) is a critical challenge to the success of total knee replacement (TKR) prostheses. Polyethylene wear debris can elicit a macrophage response within the body and lead to aseptic loosening, one of the most common reasons for revision of TKR

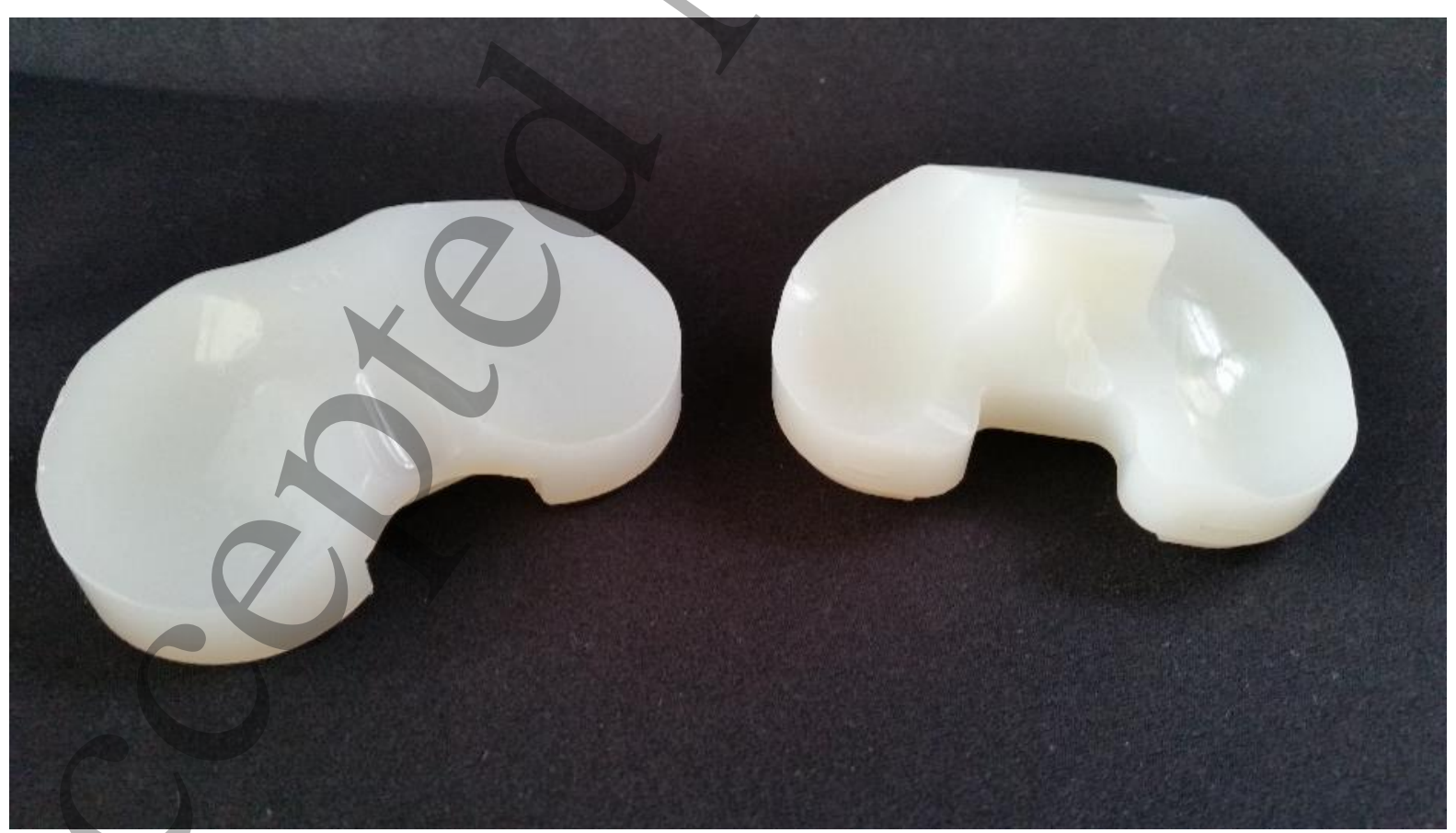

Figure 1 - Example of CR type $(L)$ and PS type $(R)$ UHMWPE tibial inserts showing stabilisation peg

implant. It is difficult when measuring wear on UHMWPE to explicitly determine that the quantity being measured is solely a result of wear, due to deformation and creep. This paper describes a study which analyses worn and unworn regions of a TKR implant with respect to their areal surface topographical parameters using a non-contact optical measurement system. As well as studying the worn and unworn 
areas of the implants, the study also compares retrieved implants to those that have had their wear simulated. Variation in different designs was also studied, these being implants of either a posterior stabilised or cruciate retaining design.

Total knee replacement is one of the most common elective surgeries in the world with three quarters of a million performed in the UK alone between 2003 and 2014. It is expected to increase by over $650 \%$ in the next 15 years [1], whilst revision procedures are expected to undergo a five-fold increase [2]. Among these revisions, the main cause of failure is likely to be aseptic loosening, as evidenced by the National Joint Registry's data showing that $41.2 \%$ of revisions were as a result of aseptic loosening between 2003 and 2014. [3] This aseptic loosening occurs as a result of an immune response to UHMWPE wear particles [4]. These wear particles may be released from the surface of the implant to other areas of the joint, leading to an immune system response and causing osteoclastic resorption of the bone, causing aseptic loosening.[5, 6]

UHMWPE has seen incredible success in TKR due to a number very desirable properties such as good mechanical strength and biocompatibility, as well as good wear resistance. The gold standard in TKR remains as a UHMWPE tibial insert in a metallic tray interfacing with a much harder metallic femoral component. This relationship means that it is highly likely that the UHMWPE component will wear in a greater volume than the metallic component. TKR prostheses come in a wide variety of designs; one of the most common debates is between a fixed bearing - where the implant is rigidly held within a metallic tibial tray - and a mobile bearing - where the implant is able to move within the tray. Various studies have been performed without consensus on which of these is more advantageous.[7-12] Likewise another variation in TKR design is whether the implant is cruciate retaining (CR) or posterior stabilised (PS). This refers to whether or not the posterior cruciate ligament (PCL) is retained post-surgery. If the PCL is removed then the implant has a stabilising peg (PS) as shown in Figure 1 with the CR type implant shown left without a stabilising peg. Studies conducted have shown no difference in either clinical effectiveness $[13,14]$ or wear $[15,16]$ between the two types.

However the material still has inherent flaws such as a lack of creep resistance. At high temperatures or under high stress UHMWPE is easily deformed. This makes the measurement of wear difficult when considering the surface of UHMWPE, as the surface may have deformed as well as worn. Numerous studies mention the contribution of creep to the difficulty of measuring UHMWPE knee prostheses [1719]. The advent of highly cross-linked polyethylene (HXLPE) and also the doping of UHMWPE with Vitamin-E for use within TKR could have an effect on this, with Takahashia et al finding that Vitamin-E doped HXLPE "significantly" improved creep resistance when compared to conventional UHMWPE $[20,21]$. However, it has been suggested that stabilisation of parts for 48-100 hours after loading can lead to $80-90 \%$ of recoverable creep relaxation [22, 23]. As this study focuses on surface topographical parameters it is deemed that creep should not be a contributory factor.

In this study focus variation microscopy (FVM) was used for the measurement of surface topography. FVM is a relatively modern form of light microscopy which similarly to confocal laser scanning microscopy, and works on the basis of analysis of depth of field [24]. Danzl et al [25] compared surface texture results gained using FVM with those gained from a traditional contact measurement system such as a CMM. It was found that FVM provided comparable results to CMM when measuring surface roughness. They also found that both methods were able to measure steep surfaces as well as surfaces with "difficult reflectance behaviour". This is a desirable characteristic due to the reflective nature of UHMWPE inserts. As mentioned, FVM works on the principle of depth of field, this is achieved by moving a microscope vertically in relation to a sample which in turn brings the part in and out of focus. It then analyses the points within the scanning range at which the part was in the best focus and uses these to reconstruct the surface at different heights.[26] FVM has been regularly cited as a method that can be used for the measurement of areal surface parameters [26, 27], providing a good basis for the measurement of surface parameters for the UHMWPE implants used in this study.

\subsection{Methods:}

2.1 Wear area mapping

A cohort of 12 wear-simulated and 5 retrieved components was measured for the purposes of this study. The wear simulated components were of two different designs; 5 DePuy LCS and 7 DePuy PFC. The 
retrieved components were of multiple different designs. These 17 components covered both cruciate retaining $(n=9)$ and posterior stabilised components $(n=8)$, and also varied in type between fixed and mobile bearing types.

In order to present tangible results in this study, it was necessary to define areas upon the components that would be considered "worn" and also those that would be considered "unworn". This was concluded through visual inspection and wear scar mapping of a number of the components. This determined that the extreme anterior condylar area and condylar region towards the centre of the implants would be considered as unworn whilst the middle of the condylar area and posterior region of the condyles would be considered as worn. In addition to this it was determined that the outer extremities of the condylar area can fall into either "worn" or "unworn" and would provide useful reference information. This information is displayed in Figure, which shows the locations of each of these. It can be shown that points 2,3,7 and 10 fall into the "unworn" category while 1,4,6 and 9 fall into "worn", whilst 5 and 8 are the outer extremities.

By defining areas as worn and unworn it is possible to use the unworn areas to define the background surface properties of the implant, which can then be compared to the properties found in the worn area to determine if there are any particular surface topographical parameters that could be used to distinguish between the two areas.

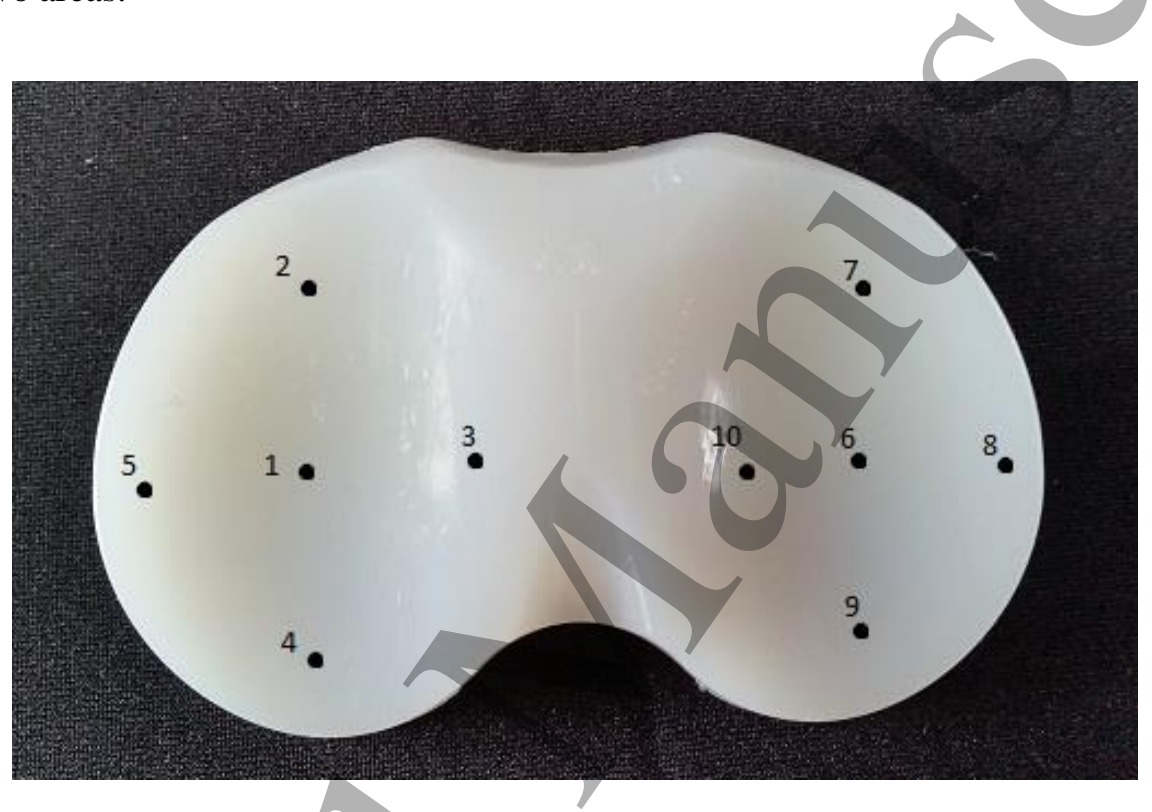

Figure 2 - Image showing measurement points on CR type retrieved implant

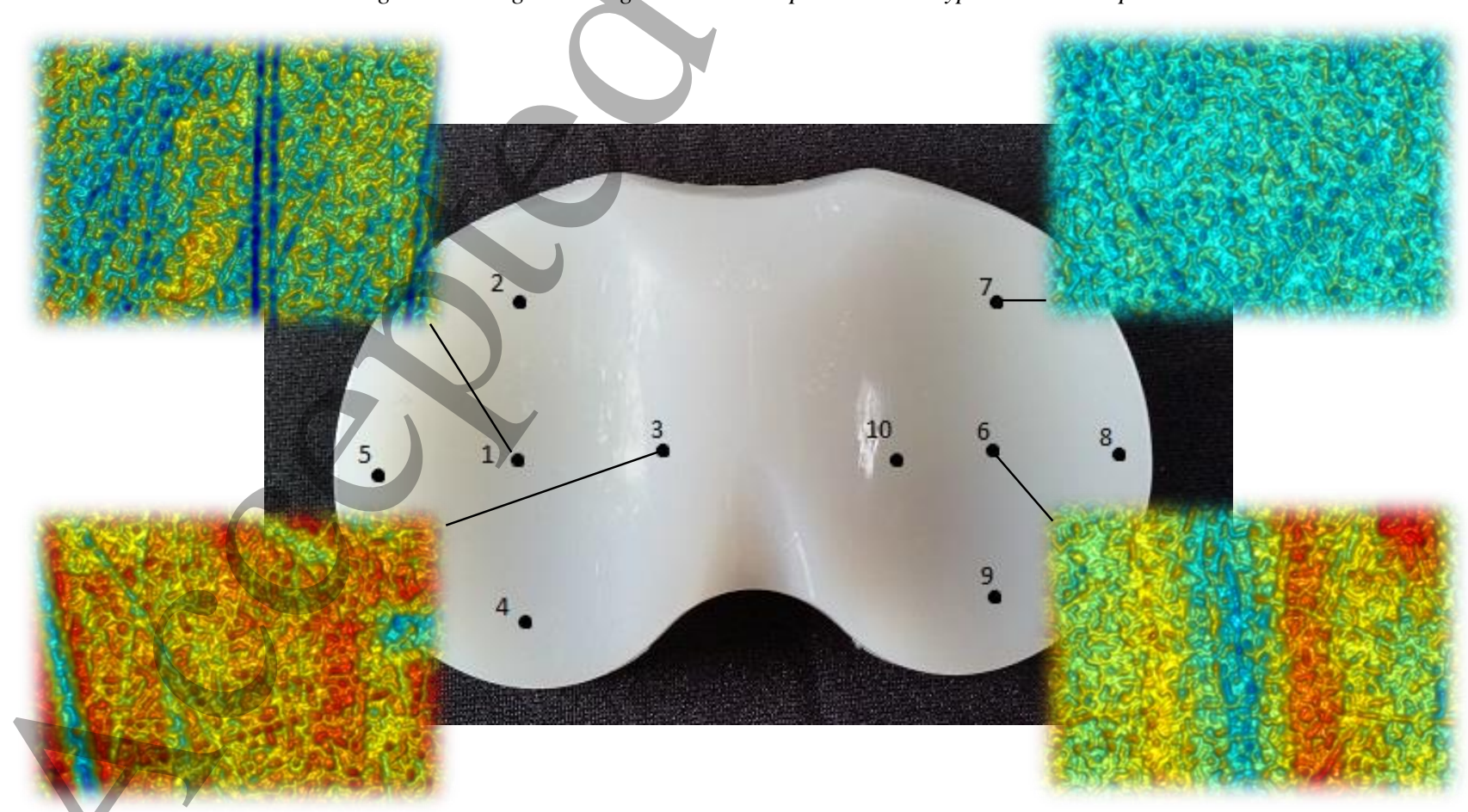




\subsection{Measurement strategy}

Measurement was performed through the use of FVM. The FVM machine used was the Alicona InfiniteFocus $®$. Ten measurements were taken for each component as per Figure . Scans were taken using a 20x magnification lens. Due to the highly reflective nature of the implant surface scans were taken using a very high contrast ratio with low brightness to avoid glass-effect on the surface and ensure no penetration through the implant surface. Based on previous experience, scans used a lateral resolution of $2.94 \mu \mathrm{m}$ and a vertical resolution of 0.04 to $0.05 \mu \mathrm{m}$. This led to approximately $4 \times 10^{5}$ data points over a scanning area of approximately 710 x $540 \mu \mathrm{m}$ for each measurement.

These measurements were then taken to surface analysis software Surfstand (University of Huddersfield, UK) to establish the surface topographical parameters. Each set of scan data was levelled and then filtered to be fitted to a second order polynomial surface. Any noisy scan data was also removed at this point, i.e. data spiking or pitting. Surface areal topographical parameters were then exported for eách dataset. Figure shows examples of the data from the SurfStand software. It can be seen that from visual inspection it appears that the worn areas (symbolised by 1 and 6) show clear unidirectional scratching, whereas the unworn areas (3 and 7) show a more random pattern.

\subsection{Surface Analysis}

ISO 25178 defines the parameters used to measure surface texture. This long list of surface parameters was then cut down to a set of parameters that would be applicable to this study. Numerous parameters were identified as having none significant differences and were therefore excluded from the study. Nine different parameters were identified to be analysed for this study. These were; $S q$, the root mean squared (RMS) height of the surface; Ssk, the surface skewness; Sku, the surface kurtosis; $S p$, the height of the surface's maximum peak; $S v$, the depth of the surface's deepest valley; $S z$, the maximum peak-valley height; $S \delta q$, the RMS overall surface slope and $S a$, the average roughness across the surface. [28] Despite not being present in ISO25178, $S \delta$, the summit density i.e. number of summits per unit area was also chosen as initial analysis suggest that $S \delta$ s showed great variation. It was also considered whether there was any variation in parameters between implants of CR types and PS types, as well as whether there was any significant differences between wear-simulated or retrieved implants. The cohort used for this study was unsuitable to compare the outcomes of fixed or mobile bearing knees as all components were of a fixed bearing type.

\subsection{Results:}

\subsection{RMS Surface Height ( $S q)$}

When the values of $S q$ were compared it was found that worn areas of the implant show lower values of $S q$ than in unworn areas. This suggests that worn areas are smoother than unworn areasWhen comparing the values across implant types it was found that CR type implants had $S q$ values between 20 and $40 \%$ lower than those given by PS type implants. No significant difference was found in $S q$ between wear simulated components and retrieved components.

\subsection{Surface Skewness (Ssk)}

The results gained from comparing $S s k$ values presented some unusual patterns. It was found that while CR type implants nearly always demonstrate a negatively skewed surface i.e. indicating a valley dominated surface whilst PS type implants generally showed a fairly neutral skewness, generally tending towards a very small positive. No difference was noted in general between wear simulated and retrieved implants of the same type.

There was no noticeable difference in $S s k$ between the worn and unworn areas of the implant, indicating the $S s k$ may not be a suitable indicator for wear regions.

\subsection{Surface Kurtosis (Sku)}

The surface kurtosis of a perfectly Gaussian surface is 3. When looking at $S k u$ in this study it was found that most measurements found values that were greater than 3 indicating a sharp peak-dominated surface. It was found that in general worn areas displayed values closer to 3 than unworn areas, albeit not significantly closer. It was found that CR type implants generally produced values of $S k u$ that were $15 \%$ higher than PS type implants across wear simulated and retrieved implants. No difference was found between wear simulated and retrieved implants. 
higher values than CR type prostheses with values generally 30\% greater for PS type implants. There was no difference found between wear simulated or retrieved implants, but it is worth noting that within the group of wear simulated components, the PFC (PS) implants had significantly higher values than those found for the LCS (CR) type devices. This trend also applied within the retrieved implants but with limited evidence for PS type devices. It was generally noted that worn areas had lower values of $S p$.

\subsection{Deepest Valley on Surface ( $S v)$}

Comparing the values of deepest valley on a surface it was found that in general worn areas display less deep valleys, generally about half the value of those found in unworn areas. In general it was seen that there was no real difference between CR and PS type devices in $S v$. It was noted that retrieved implants and wear simulated implants exhibited similar values.

\subsection{Peak to Valley Height (Sz)}

As would be suggested by the results shown for $S p$ and $S v$, worn areas showed much lower values of $S z$ than unworn areas. It was noted that points 2 and 7 (as shown in Figure ) showed much higher values than most other areas on the implants, these are unworn areas.

Again, as 4.4 and 4.5 suggest, with PS devices having larger peaks, and there being comparably deep valley, there is a general trend for larger $S z$ values in PS type implants. This is of a similar magnitude to the $S p$ value relationship. No significant difference was found between wear simulated and retrieved implants in the values of $S z$.

\subsection{Peak Density (Sds)}

When studying $S d s$ values upon each measurement it was found that in general worn areas show lower values, suggesting less peaks per unit area. Interestingly, it was also shown that retrieved components consistently show lower values of $S d s$ than wear simulated components. It was found that on average wear simulated components showed $16 \%$ higher values than retrievals. It was also found that PS type implants showed much higher values of $S d s$ than $\mathrm{CR}$ devices. This trend appeared both within the wear simulated and retrieved implants.

\subsection{RMS Surface Slope (Sdq)}

The results for $S d q$ again showed similar results to a lot of the parameters studied in that worn areas appeared to show a lower value than unworn areas. However all values were relatively small with most values less than 0.3 degrees indicating that the overall surface does not have significant slope. When comparing $S d q$ values for PS and CR implants no significant difference was noted. This was also the case when comparing wear-simulated components and retrievals.

\subsection{Surface Roughness ( $\mathrm{Sa}$ )}

Surface roughness was again found to be lower in worn areas, similarly to Sq. When comparing values it was found that there was no significant difference between wear simulated or retrieved implants.

However it was found that in general PS implants show higher values than CR prostheses, similarly to as was found in $S q$, roughly $25 \%$ higher in the case of PS.

\subsection{Discussion:}

This study attempts to distinguish between worn and unworn areas of a UHMWPE tibial inserts through an analysis of each areas surface topographical parameters. Nine different parameters were selected for this study and each has been compared for worn and unworn areas. In addition to this, comparisons were also made between wear-simulated and retrieved implants as well as those of a CR or PS type.

\subsection{Comparison of topography across worn and unworn areas}

When comparing the related parameters of $S q$ and $S a$ it was found that in general worn areas showed lower values of this indicating a smoother surface. This would be expected as the bearing surface of the 
implant underwent wear and would take on a polished appearance

It is interesting to consider the parameters $S k u$ and $S p$ together as this gives an indication of the peak behaviour and characterisation of the surface. It was noted that in general worn areas showed values of $S k u$ that were nearer to 3, a Gaussian surface, than unworn areas. This would suggest that the worn surface contains less sharp peaks and therefore has smoother peaks than the unworn areas. It is then noted that worn areas generally showed lower values of $S p$, indicating smaller peaks than unworn areas. It is possible to hypothesise that the act of wear may perhaps smooth these peaks therefore making the peaks smaller than they would be in unworn areas.

$S v$, the depth of valley on the surface was found to be significantly lower on worn areas of the surface as opposed to unworn areas. As it has been noted, $S q$ is shown to be much lower for worn surfaces indicating an overall lowering of the mean surface. This combined with the general smoothing and reduction of peaks upon the surface may lead to the valleys of the surface being reduced. If this was true it would be expected that surface skewness would begin to tend towards zero. However, no significant difference was found in skewness between worn and unworn areas. Similarly no comments of note were found regarding $S d q$, as the values were very similar for worn and unworn areas.

The $S d s$ values of summit density were found to be much lower in worn areas. This suggests that postwear there is a reduction in the number of peaks per unit area on the implant surface. This again suggests a reduction in peak height and smoothing, as was suggested by the values of $S k u$ and $S p$.

\subsection{Comparison of topography between wear-simulated and retrieved components}

By studying the surface topography of wear-simulated components and comparing these to retrieved components the efficacy of wear simulating techniques can be evaluated. Theoretically there should be no difference in topographical properties between the two types.

This was indeed the case for a number of the topographical parameters. In terms of surface roughness, it was found that for $S q$ and $S a$ there was little or no difference in values between wear-simulated and retrieved components, it was generally shown that the bigger difference occurred between CR and PS types, as will be discussed later. One observation is that retrieved implants appeared to show a smaller difference between worn and unworn areas than wear-simulated components. Again when considering the surface skewness it was found that there was no difference between wear simulated or retrieved implants of the same CR or PS design. This was the same for surface kurtosis where it was found that wear-simulated and retrieved components of the same type were very comparable. This was also the case for the related parameters $S p, S v$ and $S z$.

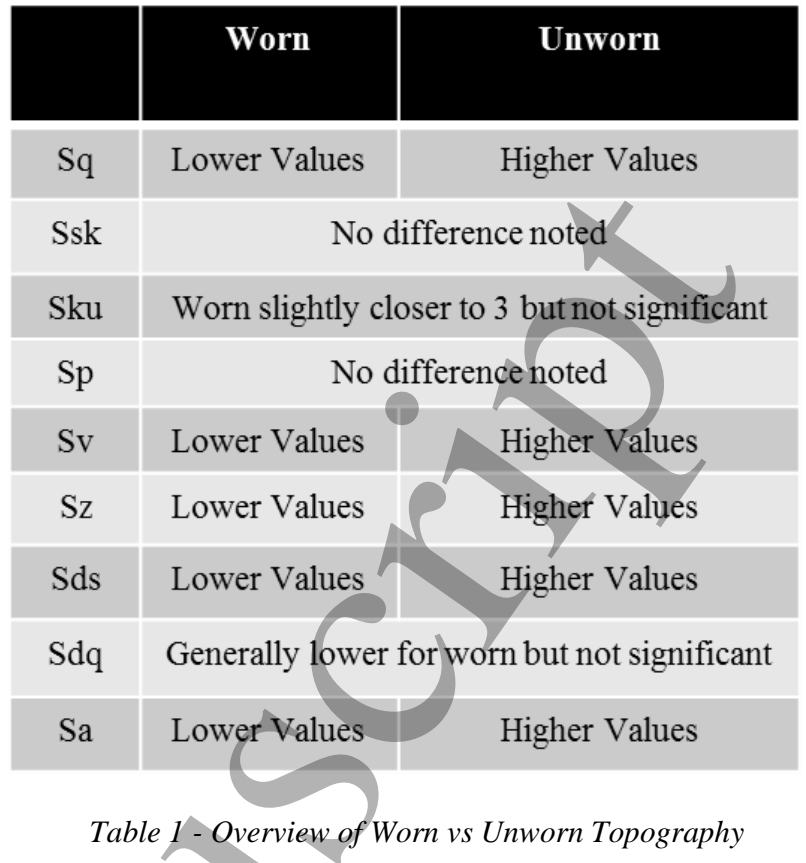

\begin{tabular}{|c|c|c|}
\hline & $\begin{array}{l}\text { Posterior Stabilised } \\
\qquad(\mathrm{n}=6)\end{array}$ & $\begin{array}{l}\text { Cruciate Retaining } \\
\qquad(\mathrm{n}=\mathbf{1 1})\end{array}$ \\
\hline $\mathrm{Sq}$ & Higher Values & Lower Values \\
\hline Ssk & Small Positive Skew & Negatively Skewed \\
\hline $\mathrm{Sku}$ & \multicolumn{2}{|c|}{ All values above $3, \mathrm{CR}$ generally higher than PS } \\
\hline $\mathrm{Sp}$ & Higher Values & Lower Values \\
\hline $\mathrm{Sv}$ & \multicolumn{2}{|c|}{ No significant difference noted } \\
\hline $\mathrm{Sz}$ & Higher Values & Lower Values \\
\hline Sds & Higher Values & Lower Values \\
\hline Sdq & \multicolumn{2}{|c|}{ No significant difference noted } \\
\hline $\mathrm{Sa}$ & Higher Values & Lower Values \\
\hline
\end{tabular}

Table 2 - Overview of PS vs CR Topography

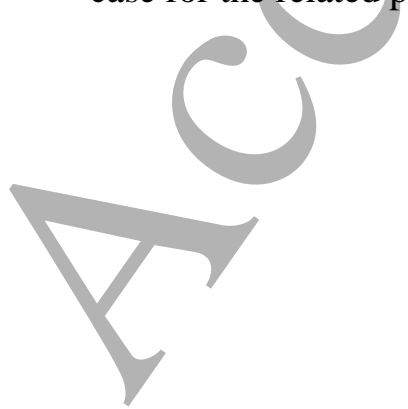


The major difference between wear-simulated and retrieved implants was found in the summit density $S d s$ parameter. It was found that retrieved components exhibited significantly lower values of $S d s$ than both types of wear-simulated components. However, as shown in Figure, it may well be that three high $S d s$ value simulated components account for this difference, whilst the other simulated implants display similar $S d s$ values to the retrieved implants.

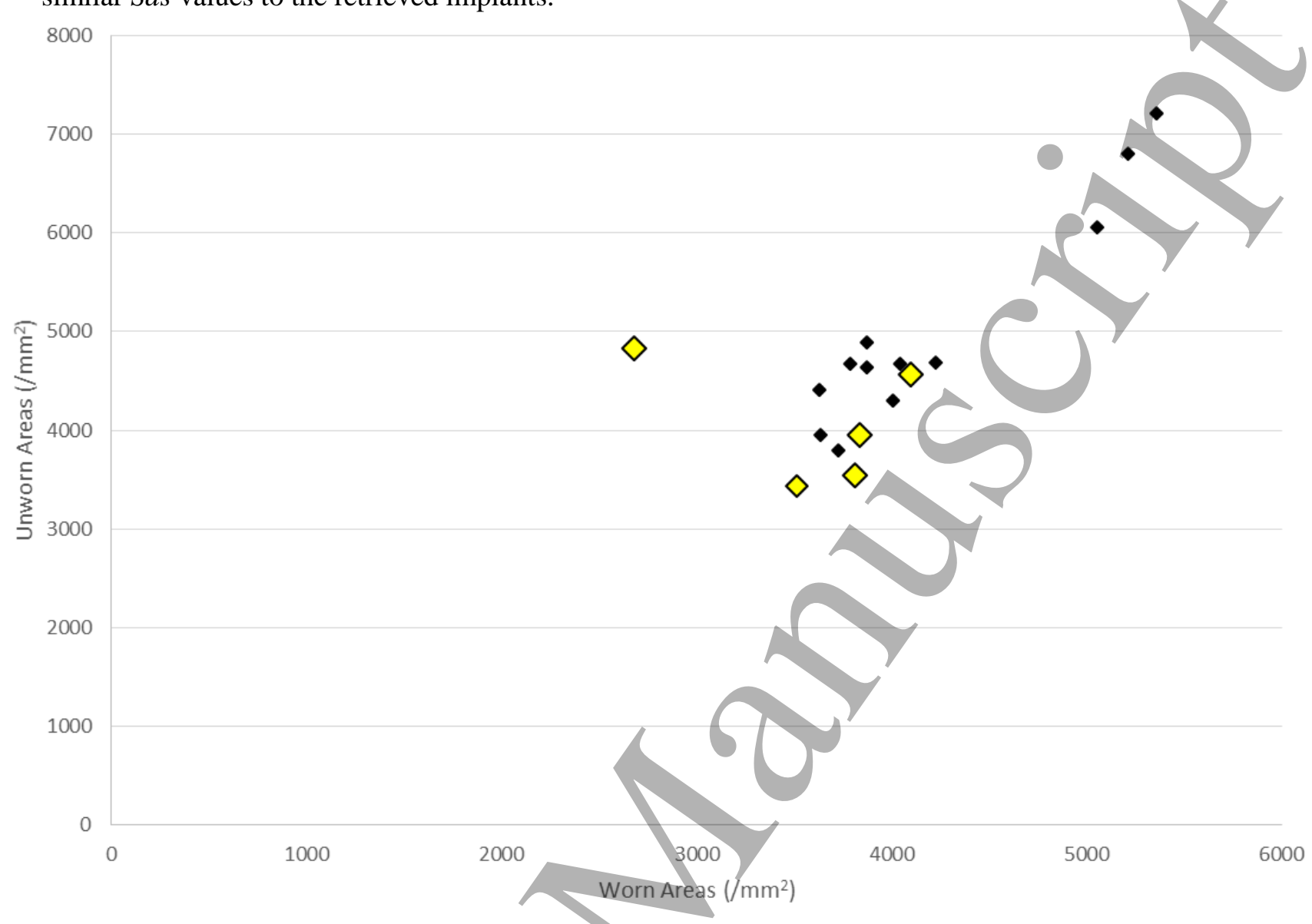

Figure 4 - Adaptation of graph showing location of retrieved implants within Sds dataset (shown in yellow)

This is shown in Figure where it can be seen that retrieved implants were generally the smallest values across all implants. No difference was noted across the $S d q$ values.

As shown, the topographical data given by retrieved implants appears to correlate well with wearsimulated components suggesting that the data gained from the wear-simulated components is accurate and reliable.

\subsection{Comparison of topography between CR and PS type implants}

As previously mentioned, numerous studies have been performed to distinguish if there is any discernable advantage to using a cruciate retaining or posterior stabilised type of UHMWPE implant[1316]. None of these studies found any noticeable advantage between the two. However, this study has shown that the different types of implant have some very stark differences in topographical properties. All patterns of result presented were consistent across wear-simulated and retrieved implants. Firstly considering the surface roughness parameters $S q$ and $S a$. It was found that in both worn and unworn areas, the PS type implants exhibited much higher values of both $S q$ and $S a$, in the magnitude of $20 \%$ higher in worn areas and $40 \%$ higher in unworn areas. From this it can be surmised that CR implants showed a much less significant difference between worn and unworn areas than PS type devices.

Considering the next set of parameters that relate to the peaks and valleys of the surface it was found that there was a significant difference in surface skewness between CR and PS type implants. It was found that while CR implants tend to be slightly negatively skewed, indicating a valley dominated surface, PS type devices appear to show a slight positive skew which would indicate a peak dominated surface. This is reinforced by the $S p$ values which show PS implants as having much higher peaks than those found on CR type devices. There was little difference between the two types in relation to the maximum valley 
depth. The combination of $S p$ and $S v$ means that in general PS type inserts appear to show a larger peak to valley value.

As mentioned in 5.2, retrieved implants appear to show much lower values of $S d s$ than wear-simulated implants. Figure highlights the location of the PS type implants within the full dataset. As shown, in general PS type implants show higher values of $S d s$ than CR type. However, the point shown in blue is a retrieved PS type implant. It can be seen that this implant displays a much lower values of $S d s$ in worn areas than any other component that was tested. Similar to the comparison of retrieved and wear simulated components, no significant difference was found between PS and CR type implants when considering the $S d q$ parameter.
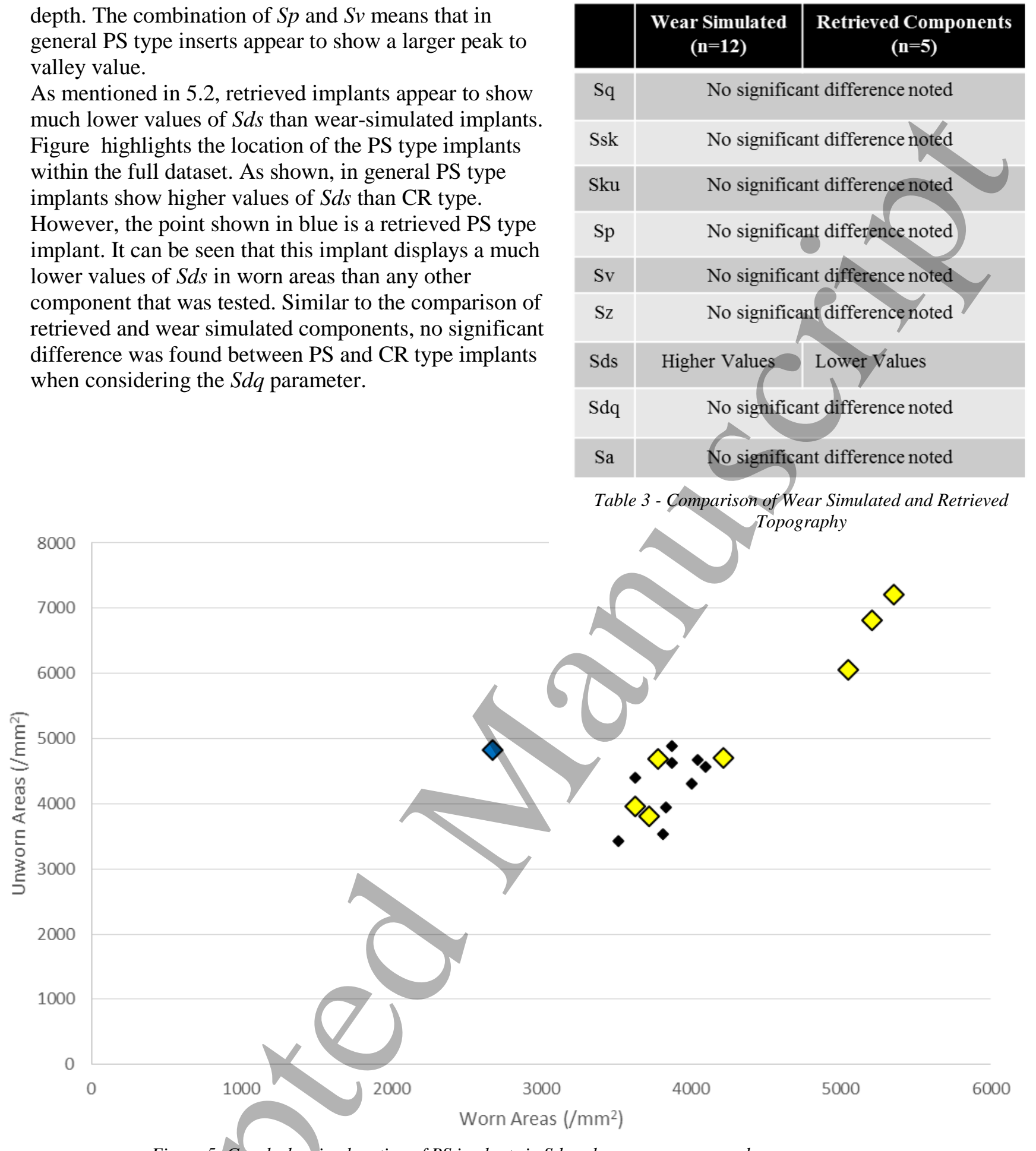

Figure 5-Graph showing location of PS implants in Sds values across worn and unworn areas.

\subsection{Conclusions:}

This study has shown that there are topographical differences between certain aspects of UHMWPE inserts used within TKR. Our results suggest that there are surface topographical properties that vary between worn and unworn areas upon an implants condylar surface. The most striking is the difference in surface kurtosis. It appears that worn areas of implants show kurtosis values closer to a typical Gaussian surface and also show generally lower peaks than unworn areas suggesting that the peaks on the surface have been flattened giving less sharp peaks on the surface. It also appears that worn areas tend to have a smooth surface texture as suggested by $S q$ and $S a$. In addition to this it seems that worn areas tend to have a lower summit density on the surface which also fits with this pattern of peak smoothing and general surface smoothing.

As well as comparing worn and unworn areas this study also considered the topographical differences between wear-simulated and retrieved implants. In general, there were not wide ranging differences 
between the respective surface parameters of wear-simulated and retrieved prostheses. However, there was a noticeable drop in surface summit density on retrieved implants.

As a third study, the surface differences between cruciate retaining and posterior stabilised type devices were compared, with certain parameters showing very different characteristics across the two types. It appeared that PS type implants showed a generally rougher, peak dominated surface whereas CR type implants showed a smoother more neutrally skewed surface. These patterns appear to be consistent regardless of whether the component was wear-simulated or retrieved.

In conclusion, this paper has discussed observations of variation in surface topography between worn and unworn areas, wear-simulated and retrieved and CR and PS total knee replacement prostheses. The data appears to have shown some trends and patterns and applying the same methodology to a more comprehensive and cohesive cohort of implants should lead to a more defined analysis of the surface topographical variation between these respective areas.

\section{References:}

[1] Kurtz S M, Lau E, Ong K, Zhao K, Kelly M and Bozic K J 2009 Future young patient demand for primary and revision joint replacement: National projections from 2010 to 2030 Clinical Orthopaedics and Related Research 467 2606-12

[2] Bhandari M, Smith J, Miller L E and Block J E 2012 Clinical and Economic Burden of Revision Knee Arthroplasty Clinical Medicine Insights: Arthritis and Musculoskeletal Disorders 2012 8994

[3] NJR 2015 12th Annual Report (2015) : National Joint Registry for England Wales, Northern Irelands and the Isle of Man (Hemel Hempstead: National Joint Registry) p 183

[4] Gladkis L G, Timmers H, Scarvell J M and Smith P N 2011 Detailed three-dimensional size and shape characterisation of UHMWPE wear debris Wear 270 455-63

[5] Holleyman R J, Scholes S C, Weir D, Jameson S S, Holland J, Joyce T J and Deehan D J 2015 Changes in surface topography at the TKA backside articulation following in vivo service: a retrieval analysis Knee Surgery, Sports Traumatology, Arthroscopy 23 3523-31

[6] Wooley P H and Schwarz E M 2004 Aseptic loosening Gene Therapy 11 402-7

[7] Oh K J, Pandher D S, Lee S T, Lee S H and Sung Joon S D 2009 Meta-Analysis Comparing Outcomes of Fixed-Bearing and Mobile-Bearing Prostheses in Total Knee Arthroplasty The Journal of Arthroplasty 24 873-84

[8] Bo Z-d, Liao L, Zhao J-m, Wei Q-j, Ding X-f and Yang B 2014 Mobile bearing or fixed bearing? A meta-analysis of outcomes comparing mobile bearing and fixed bearing bilateral total knee replacements The Knee $\mathbf{2 1} 374-81$

[9] Smith T O, Hing C B, Davies L and Donell S T 2009 Fixed versus mobile bearing unicompartmental knee replacement: A meta-analysis Orthopaedics and Traumatology: Surgery and Research 95 599-605

[10] Wen Y, Liu D, Huang Y and Li B 2011 A meta-analysis of the fixed-bearing and mobile-bearing prostheses in total knee arthroplasty Archives of Orthopaedic and Trauma Surgery 131 1341-50

[11] Smith H, Jan M, Mahomed N N, Davey J R and Gandhi R 2011 Meta-Analysis and Systematic Review of Clinical Outcomes Comparing Mobile Bearing and Fixed Bearing Total Knee Arthroplasty Journal of Arthroplasty 26 1205-13

[12] Li Y-L, Wu Q, Ning G-Z, Feng S-Q, Wu Q-L, Li Y and Hao Y 2014 No difference in clinical outcome between fixed- and mobile-bearing TKA: a meta-analysis Knee Surgery, Sports Traumatology, Arthroscopy 22 565-75

[13] Li N, Tan Y, Deng Y and Chen L 2014 Posterior cruciate-retaining versus posterior stabilized total knee arthroplasty: a meta-analysis of randomized controlled trials Knee Surgery, Sports Traumatology, Arthroscopy 22 556-64

[14] Molt M, Toksvig-Larsen S, Division, III, Medicinska f, Faculty of M, Sektion, III, Department of Clinical Sciences L, Department of O, Lunds u, Ortopedi L, Institutionen för kliniska vetenskaper L and Lund U 2014 Similar early migration when comparing CR and PS in Triathlon TM TKA: A prospective randomised RSA trial The Knee 21 949-54

[15] Berry D J, Currier J H, Mayor M B and Collier J P 2012 Knee Wear Measured in Retrievals: A Polished Tray Reduces Insert Wear Clinical Orthopaedics and Related Research 470 1860-8

[16] Wang A, Yau S-S, Essner A, Herrera L, Manley M and Dumbleton J 2008 A Highly Crosslinked UHMWPE for CR and PS Total Knee Arthroplasties The Journal of Arthroplasty 23 559-66

[17] Saikko V, Ahlroos T and Calonius O 2001 A three-axis knee wear simulator with ball-on-flat contact Wear 249 310-5 
[18] Affatato S, Modena E, Carmignato S, Grupp T M and Taddei P 2013 Quantification of Wear Rates and Plastic Deformation on Mobile Unicompartmental UHMWPE Tibial Knee Inserts Tribology Letters 52 57-65

[19] Quinci F, Dressler M, Strickland A M and Limbert G 2014 Towards an accurate understanding of UHMWPE visco-dynamic behaviour for numerical modelling of implants Journal of the mechanical behavior of biomedical materials 32 62-75

[20] Takahashi Y, Tateiwa T, Shishido T, Masaoka T, Kubo K and Yamamoto K 2016 Size and thickness effect on creep behavior in conventional and vitamin E-diffused highly crosslinked polyethylene for total hip arthroplasty Journal of the mechanical behavior of biomedical materials 62 399-406

[21] Kurtz S M 2004 The UHMWPE handbook: ultra-high molecular weight polyethylene in total joint replacement (Amsterdam;London;: Elsevier Academic Press)

[22] Bills P, Brown L, Jiang X and Blunt L 2005 A metrology solution for the orthopaedic industry Journal of Physics: Conference Series 13 316-9

[23] Dowson D, McCullage P and Wright V 1991 UHMWPE as a biomaterial in orthopaedic surgery, ed W HG, et al. (Germany: Hogrefe \& Huber Publishers)

[24] Kapłonek W, Nadolny K and Królczyk G M 2016 The Use of Focus-Variation Microscopy for the Assessment of Active Surfaces of a New Generation of Coated Abrasive Tools Measurement Science Review 16 42-53

[25] Danzl R, Helmli F and Scherer S 2011 Focus Variation - a Robust Technology for High Resolution Optical 3D Surface Metrology Journal of Mechanical Engineering 57 245-56

[26] Macdonald D A 2014 The application of focus variation microscopy for lithic use-wear quantification Journal of Archaeological Science 48 26-33

[27] Hiersemenzel F, Petzing J N, Leach R K, Helmli F S and Singh J/2012 Areal texture and angle measurements of tilted surfaces using focus variation methods Proceedings of the $3 \mathrm{rd}$ International conferences on Surface Metrology

[28] 2016 BS EN ISO 25178-1:2016: Geometrical product specifications (GPS). Surface texture: Areal. Indication of surface texture. British Standards Institute) 


\section{1}

2

8

9

10

11

12

13

14

15

16

17

18

19

20

21

22

23

24

25

26

27

28

29

30

31

32

33

34

35

36

37

38

39

40

41

42

43

44

45

46

47

48

49

50

51

52

53

54

55

56

57

58

59

60

\section{Appendix A: Raw Data}

\begin{tabular}{|c|c|c|c|c|c|c|c|c|c|c|c|c|c|c|c|c|c|}
\hline & $q(u m)$ & Ssk & Sku & Sp(um) & Sv(um) & z(um) & $\mathrm{Sds}\left(1 / \mathrm{mm}^{\wedge} 2\right)$ & Sdq & Ssc(1/um) & Sdr(\%) & Spk(um) & Sk(um) & Svk(um) & Smr1(\%) & Smr2(\%) & S5z(um) & a(um) \\
\hline LCS1-1 & 0.455 & -0.139 & 3.243 & 1.833 & 2.505 & 4.338 & $3.81 E+03$ & 0.122 & 0.047 & 0.75 & 0.428 & 1.173 & 0.508 & 8.8 & 89.8 & 3.684 & 0.36 \\
\hline LCS1-10 & 522 & -0.125 & 3.679 & 2.95 & 4.185 & 7.135 & $4.43 E+03$ & 0.156 & 0.063 & 1.204 & 0.542 & 1.302 & 0.627 & 9.5 & 89.6 & 4.523 & 0.408 \\
\hline LCS1-2 & 693 & -0.315 & 1.334 & 6.627 & 23.274 & 29.901 & $5.52 \mathrm{E}+03$ & 0.267 & .116 & 3.326 & 0.777 & 1.748 & 1.233 & 9.6 & 90 & 6.659 & 0.542 \\
\hline LCS1-3 & 0.472 & -0.105 & 3.898 & 3.677 & 4.554 & 8.231 & $4.46 \mathrm{E}+03$ & 0.144 & 0.061 & 1.033 & 0.509 & 1.174 & 0.593 & 9.7 & 89.8 & 4.237 & 0.368 \\
\hline LCS1-4 & 0.374 & -0.15 & 3.781 & 2.207 & 2.418 & 4.625 & $4.07 \mathrm{E}+03$ & 0.102 & 0.041 & 0.521 & 0.403 & 0.908 & 0.462 & 9.3 & 88.9 & 3.411 & 0.29 \\
\hline LCS1-5 & 0.595 & 0.109 & 3.36 & 3.1 & 2.367 & 5.467 & $3.61 \mathrm{E}+03$ & 0.156 & 0.059 & 1.205 & 0.661 & 1.491 & 0.581 & 10.1 & 89.9 & 4.762 & 0.467 \\
\hline LCS1-6 & 0.467 & 0.17 & 3.335 & 2.168 & 2.686 & 4.854 & $4.04 \mathrm{E}+03$ & 0.125 & 0.05 & 0.782 & 0.542 & 1.165 & 0.464 & 11.1 & 90.9 & 3.601 & 0.367 \\
\hline LCS1-7 & 0.77 & -0.057 & 3.906 & 4.54 & 7.428 & 11.969 & $5.15 E+03$ & 0.275 & 0.117 & 3.679 & 0.856 & 1.883 & 0.946 & 10.3 & 89.8 & 7.74 & 0.598 \\
\hline LCS1-8 & 0.561 & -0.123 & 3.212 & 3.49 & 2.782 & 6.272 & $3.85 \mathrm{E}+03$ & 0.148 & 0.054 & 1.094 & 0.56 & 1.438 & 0.612 & 8.6 & 89.1 & 4.443 & 0.445 \\
\hline LCS1-9 & 0.475 & 0.187 & 4.638 & 2.269 & 5.374 & 7.643 & $3.57 \mathrm{E}+03$ & 0.108 & 0.041 & 0.595 & 0.627 & 1.116 & 0.557 & 11.3 & 90.2 & 4.17 & 0.363 \\
\hline LCS2-1 & 0.582 & -0.085 & 3.542 & 3.688 & 3.833 & 7.522 & $3.65 \mathrm{E}+03$ & 0.146 & 0.054 & 1.059 & 0.622 & 1.431 & 0.703 & 10.4 & 89.9 & 4.752 & 0.454 \\
\hline LCS2-10 & 0.441 & 0.244 & 5.987 & 4.825 & 2.903 & 7.728 & $4.30 \mathrm{E}+03$ & 0.135 & 0.053 & 0.898 & 0.572 & 1.045 & 0.52 & 10.1 & 89.9 & 5.162 & 0.335 \\
\hline LCS2-2 & 0.346 & -0.356 & 6.053 & 2.3 & 2.579 & 4.879 & $4.31 \mathrm{E}+03$ & 0.098 & 0.032 & 0.486 & 0.438 & 0.69 & 0.576 & 9.6 & 86.7 & 3.818 & 0.249 \\
\hline LCS2-3 & 0.601 & 0.632 & 19.932 & 16.185 & 4.303 & 20.488 & $3.60 \mathrm{E}+03$ & 0.176 & 0.066 & 1.452 & 1.008 & 1.411 & 0.732 & 9.8 & 89.4 & 6.029 & 0.454 \\
\hline LCS2-4 & 0.509 & -0.089 & 3.611 & 2.368 & 3.219 & 5.588 & $4.16 \mathrm{E}+03$ & 0.136 & 0.059 & 0.934 & 0.55 & 1.234 & 0.614 & 9.3 & 88.6 & 4.462 & 0.395 \\
\hline LCS2-5 & 0.642 & -1.017 & 7.938 & 4.587 & 5.075 & 9.662 & $4.18 \mathrm{E}+03$ & 0.166 & 0.059 & 1.34 & 0.571 & 1.433 & 1.011 & 8.1 & 87.9 & 7.45 & 0.474 \\
\hline LCS2-6 & 0.281 & 0.179 & 4.184 & 2.258 & 1.661 & 3.92 & $4.38 \mathrm{E}+03$ & 0.08 & 0.034 & 0.326 & 0.345 & 0.682 & 0.301 & 10.6 & 90.1 & 2.721 & 0.217 \\
\hline LCS2-7 & 0.682 & -0.119 & 6.021 & 5.784 & 6.663 & 12.448 & $5.00 \mathrm{E}+03$ & 0.229 & 0.09 & 2.543 & 0.786 & 1.52 & 0.961 & 9.3 & 87.2 & 8.078 & 0.511 \\
\hline LCS2-8 & 0.543 & -0.415 & 3.955 & 2.614 & 3.147 & 5.761 & $4.38 \mathrm{E}+03$ & 0.16 & 0.058 & 1.256 & 0.511 & 1.283 & 0.742 & 8.8 & 87.7 & 5.086 & 0.419 \\
\hline LCS2-9 & 0.394 & -0.322 & 4.425 & 2.776 & 2.489 & 5.265 & $3.83 \mathrm{E}+03$ & 0.11 & 0.041 & 0.603 & 0.444 & 0.893 & 0.54 & 9.6 & 87.4 & 3.839 & 0.299 \\
\hline LCS3-1 & 1.066 & -0.336 & 5.429 & 5.451 & 5.746 & 11.198 & $3.38 \mathrm{E}+03$ & 0.162 & 0.055 & 1.269 & 1.465 & 2.102 & 1.474 & 12.1 & 86.7 & 9.305 & 0.773 \\
\hline LCS3-10 & 0.528 & 0.084 & 3.895 & 4 & 3.059 & 7.059 & $3.97 \mathrm{E}+03$ & 0.16 & 0.061 & 1.263 & 0.67 & 1.254 & 0.591 & 10.5 & 89.1 & 5.111 & 0.407 \\
\hline LCS3-2 & 0.324 & -0.007 & 5.578 & 2.177 & 4.331 & 6.508 & $4.82 \mathrm{E}+03$ & 0.099 & 0.039 & 0.483 & 0.433 & 0.72 & 0.485 & 10.9 & 89.7 & 3.413 & 0.241 \\
\hline LCS3-3 & 0.468 & 0.067 & 4.186 & 4.36 & 3.445 & 7.805 & $4.13 \mathrm{E}+03$ & 0.127 & 0.051 & 0.799 & 0.598 & 1.114 & 0.559 & 10.5 & 89.5 & 4.081 & 0.36 \\
\hline LCS3-4 & 1.002 & -0.31 & 2.65 & 4.314 & 3.352 & 7.666 & $3.23 E+03$ & 0.122 & 0.047 & 0.748 & 0.66 & 2.526 & 1.063 & 8.4 & 85.8 & 5.811 & 0.807 \\
\hline LCS3-5 & 0.538 & -0.569 & 3.91 & 2.041 & 2.512 & 4.552 & $3.83 E+03$ & 0.126 & 0.043 & 0.793 & 0.46 & 1.241 & 0.762 & 8.8 & 86.7 & 4.082 & 0.414 \\
\hline LCS3-6 & 0.523 & -0.398 & 4.519 & 4.668 & 6.152 & 10.819 & $3.88 \mathrm{E}+03$ & 0.134 & 0.048 & 0.885 & 0.538 & 1.288 & 0.709 & 9.1 & 88.8 & 3.976 & 0.407 \\
\hline LCS3-7 & 0.487 & -0.818 & 7.116 & 2.738 & 5.234 & 7.971 & $4.71 \mathrm{E}+03$ & 0.153 & 0.059 & 1.147 & 0.536 & 1.003 & 0.808 & 10.9 & 87.5 & 6.294 & 0.354 \\
\hline \begin{tabular}{|l|} 
LCS3-8 \\
\end{tabular} & 0.552 & -0.428 & 4.079 & 3.506 & 4.66 & 8.166 & $3.78 \mathrm{E}+03$ & 0.135 & 0.051 & 0.911 & 0.515 & 1.34 & 0.753 & 8.9 & 88.3 & 4.841 & 0.429 \\
\hline LCS3-9 & 0.501 & -10.308 & 264.411 & 2.185 & 14.754 & 16.94 & $4.03 \mathrm{E}+03$ & 0.135 & 0.04 & 0.732 & 0.47 & 0.898 & 0.781 & 10.4 & 89.6 & 8.937 & 0.3 \\
\hline LCS4-1 & 0.658 & 0.371 & 4.027 & 3.34 & 2.694 & 6.034 & $3.49 \mathrm{E}+03$ & 0.122 & 0.044 & 0.748 & 1.05 & 1.439 & 0.701 & 11.3 & 88.4 & 5.106 & 0.494 \\
\hline LCS4-10 & 0.499 & -0.032 & 3.801 & 2.764 & 2.906 & 5.671 & $4.23 \mathrm{E}+03$ & 0.131 & 0.054 & 0.862 & 0.561 & 1.234 & 0.564 & 9.6 & 89.9 & 4.487 & 0.388 \\
\hline LCS4-2 & 0.454 & 0.01 & 4.288 & 2.949 & 3.32 & 6.269 & $4.89 \mathrm{E}+03$ & $0: 144$ & 0.063 & 1.037 & 0.565 & 1.079 & 0.568 & 10.1 & 89.8 & 4.391 & 0.347 \\
\hline LCS4-3 & 0.374 & -0.257 & 3.475 & 3.177 & 2.242 & 5.419 & $4.14 \mathrm{E}+03$ & 0.099 & 0.039 & 0.488 & 0.375 & 0.941 & 0.448 & 8.8 & 88.8 & 3.034 & 0.294 \\
\hline \begin{tabular}{|l|} 
LCS4-4 \\
\end{tabular} & 0.411 & 0.255 & 3.721 & 2.448 & 4.18 & 6.628 & $3.60 \mathrm{E}+03$ & 0.109 & 0.043 & 0.601 & 0.534 & 0.984 & 0.471 & 12.2 & 91.2 & 3.709 & 0.319 \\
\hline LCS4-5 & 0.928 & -0.446 & 4.613 & 3.721 & 4.079 & 7.8 & $3.36 \mathrm{E}+03$ & 0.139 & 0.05 & 0.961 & 1.087 & 1.856 & 1.601 & 11.3 & 87.3 & 7.438 & 0.676 \\
\hline \begin{tabular}{|l|} 
LCS4-6 \\
\end{tabular} & 0.376 & -0.163 & 7.357 & 4.394 & 3.643 & 8.037 & $4.27 \mathrm{E}+03$ & 0.099 & 0.037 & 0.49 & 0.427 & 0.864 & 0.542 & 9 & 88.1 & 4.054 & 0.283 \\
\hline LCS4-7 & 0.957 & -0.227 & 6.961 & 6.102 & 16.626 & 22.728 & $5.27 \mathrm{E}+03$ & 0.354 & 0.142 & 5.51 & 1.267 & 2.021 & 1.583 & 11.2 & 88.9 & 12.036 & 0.697 \\
\hline \begin{tabular}{|l|} 
LCS4-8 \\
\end{tabular} & 0.508 & -0.549 & 4.759 & 4.594 & 2.781 & 7.375 & $3.86 \mathrm{E}+03$ & 0.129 & 0.041 & 0.829 & 0.565 & 1.123 & 0.765 & 7.6 & 86 & 4.938 & 0.384 \\
\hline LCS4-9 & 0.396 & 0.329 & 15.943 & 10.803 & 3.56 & 14.363 & $4.14 \mathrm{E}+03$ & 0.103 & 0.039 & 0.526 & 0.677 & 0.859 & 0.567 & 9.7 & 87.9 & 4.339 & 0.29 \\
\hline LCS5-1 & 0.419 & -0.583 & 3.927 & 2.884 & 2.385 & 5.269 & $4.09 \mathrm{E}+03$ & 0.111 & 0.04 & 0.627 & 0.369 & 0.979 & 0.604 & 7.7 & 86.5 & 3.373 & 0.324 \\
\hline LCS5-10 & 0.508 & -0.206 & 5.009 & 2.647 & 11.893 & 14.54 & $4.57 \mathrm{E}+03$ & 0.16 & 0.064 & 1.244 & 0.509 & 1.279 & 0.796 & 9.1 & 89.6 & 4.535 & 0.398 \\
\hline LCS5-2 & 0.371 & -0.354 & 4.657 & 2.489 & 3.345 & 5.833 & $4.93 \mathrm{E}+03$ & 0.116 & 0.046 & 0.67 & 0.41 & 0.854 & 0.534 & 10 & 88.6 & 3.794 & 0.281 \\
\hline LCS5-3 & 0.41 & -0.298 & 4.594 & 2.393 & 5.478 & 7.871 & $4.04 \mathrm{E}+03$ & 0.113 & 0.044 & 0.643 & 0.432 & 0.981 & 0.602 & 9 & 88.7 & 3.804 & 0.315 \\
\hline LCS5-4 & 0.317 & 0.051 & 5.325 & 2.796 & 3.4 & 6.196 & 4. $10 \mathrm{E}+03$ & 0.092 & 0.04 & 0.421 & 0.423 & 0.757 & 0.404 & 10.4 & 90.7 & 3.232 & 0.242 \\
\hline LCS5-5 & 0.61 & -0.813 & 4.574 & 2.706 & 3.689 & 6.395 & $3.67 E+03$ & 0.135 & 0.046 & 0.91 & 0.45 & 1.393 & 0.958 & 7.9 & 86.6 & 5.11 & 0.466 \\
\hline LCS5-6 & 0.345 & -0.781 & 5.224 & 2.113 & 2.44 & 4.553 & $3.99 \mathrm{E}+03$ & 0.085 & 0.029 & 0.367 & 0.293 & 0.817 & 0.513 & 7.4 & 88.1 & 3.22 & 0.263 \\
\hline LCS5-7 & 1.056 & 11.13 & 214.701 & 25.369 & 4.245 & 29.614 & $5.24 \mathrm{E}+03$ & 0.408 & 0.1 & 6.688 & 1.475 & 1.605 & 0.824 & 8.9 & 89.1 & 27.704 & 0.543 \\
\hline LCS5-8 & 0.339 & -0.737 & 4.47 & 1.751 & 2.241 & 3.991 & 4.12E+03 & 0.088 & 0.032 & 0.39 & 0.279 & 0.759 & 0.552 & 8.7 & 86.9 & 2.883 & 0.257 \\
\hline LCS5-9 & 0.321 & -0.225 & 3.926 & 2.618 & 2.967 & 5.585 & $3.99 \mathrm{E}+03$ & 0.084 & 0.032 & 0.362 & 0.347 & 0.774 & 0.427 & 9.6 & 88.8 & 2.69 & 0.248 \\
\hline
\end{tabular}




\begin{tabular}{|c|c|c|c|c|c|c|c|c|c|c|c|c|c|c|c|c|c|}
\hline PFC1-1 & 0.562 & 0.276 & 2.969 & 3.661 & 2.45 & 6.11 & $3.77 \mathrm{E}+03$ & 0.115 & 0.047 & 0.671 & 0.627 & 1.425 & 0.454 & 13 & 92.3 & 3.962 & 0.45 \\
\hline PFC1-2 & 0.831 & -0.001 & 3.711 & 5.606 & 5.849 & 11.455 & $4.40 \mathrm{E}+03$ & 0.234 & 0.093 & 2.657 & 0.864 & 2.116 & 0.933 & 9.5 & 90.2 & 7.446 & 0.654 \\
\hline PFC1-4 & 0.532 & -0.119 & 3.536 & 3.608 & 4.499 & 8.107 & $3.89 \mathrm{E}+03$ & 0.142 & 0.058 & 1.005 & 0.562 & 1.348 & 0.633 & 9.1 & 89.7 & 4.457 & 0.418 \\
\hline PFC1-5 & 0.475 & 0.193 & 3.597 & 2.755 & 3.613 & 6.369 & $3.92 \mathrm{E}+03$ & 0.117 & 0.047 & 0.703 & 0.547 & 1.195 & 0.488 & 10.7 & 90.9 & 3.805 & 0.373 \\
\hline PFC1-6 & 0.556 & 0.063 & 3.284 & 2.225 & 5.741 & 7.966 & $3.86 \mathrm{E}+03$ & 0.145 & 0.061 & 1.043 & 0.575 & 1.432 & 0.603 & 10.4 & 90.9 & 4.365 & 0.441 \\
\hline PFC1-7 & 0.927 & -0.264 & 4.272 & 7.908 & 13.727 & 21.635 & $4.96 \mathrm{E}+03$ & 0.317 & 0.129 & 4.77 & 1.016 & 2.262 & 1.345 & 9.7 & 89.5 & 9.88 & 0.718 \\
\hline PFC1-8 & 0.556 & 0.028 & 3.503 & 3.996 & 6.761 & 10.758 & $3.70 \mathrm{E}+03$ & 0.125 & 0.052 & 0.788 & 0.608 & 1.446 & 0.628 & 9.1 & 90.2 & 4.789 & 0.441 \\
\hline PFC1-9 & 0.753 & 0.308 & 7.039 & 7.497 & 5.638 & 13.135 & $3.62 \mathrm{E}+03$ & 0.179 & 0.07 & 1.575 & 0.854 & 1.819 & 0.894 & 9.2 & 89.3 & 7.364 & 0.575 \\
\hline PFC2-1 & 0.61 & -0.112 & 3.146 & 3.689 & 2.628 & 6.317 & $3.66 \mathrm{E}+03$ & 0.143 & 0.055 & 1.032 & 0.586 & 1.576 & 0.635 & 8.6 & 89.3 & 4.594 & 0.484 \\
\hline PFC2-2 & 0.873 & 0.46 & 3.971 & 4.355 & 14.175 & 18.53 & $3.64 \mathrm{E}+03$ & 0.21 & 0.079 & 2.115 & 1.123 & 2.219 & 1.031 & 11.1 & 92.6 & 7.321 & 0.687 \\
\hline PFC2-4 & 0.54 & 0.166 & 3.742 & 2.569 & 2.439 & 5.008 & $3.53 \mathrm{E}+03$ & 0.129 & 0.052 & 0.829 & 0.667 & 1.312 & 0.554 & 10.2 & 89.8 & 4.627 & 0.418 \\
\hline PFC2-5 & 0.605 & 0.344 & 3.886 & 4.014 & 2.976 & 6.991 & $3.66 \mathrm{E}+03$ & 0.121 & 0.048 & 0.74 & 0.739 & 1.491 & 0.562 & 11.3 & 90.9 & 5.12 & 0.472 \\
\hline PFC2-6 & 0.75 & -0.303 & 3.95 & 2.715 & 5.64 & 8.356 & $3.46 \mathrm{E}+03$ & 0.148 & 0.059 & 1.079 & 0.721 & 1.826 & 0.95 & 10.2 & 89.5 & 5.75 & 0.582 \\
\hline \begin{tabular}{|l|} 
PFC2-7 \\
\end{tabular} & 0.63 & 0.29 & 4.221 & 4.063 & 3.849 & 7.913 & $4.27 \mathrm{E}+03$ & 0.173 & 0.068 & 1.477 & 0.808 & 1.523 & 0.636 & 10.6 & 90.1 & 6.094 & 0.486 \\
\hline PFC2-8 & 0.496 & -0.308 & 6.381 & 3.423 & 4.439 & 7.861 & $3.62 \mathrm{E}+03$ & 0.1 & 0.039 & 0.49 & 0.573 & 1.092 & 0.771 & 11.9 & 90.7 & 5.656 & 0.367 \\
\hline PFC2-9 & 0.369 & 0.183 & 3.986 & 2.266 & 1.891 & 4.157 & $3.89 \mathrm{E}+03$ & 0.092 & 0.038 & 0.425 & 0.463 & 0.9 & 0.397 & 10.3 & 90.5 & 3.467 & 0.286 \\
\hline PFC3-1 & 0.581 & -0.252 & 3.109 & 3.544 & 2.802 & 6.345 & $3.74 \mathrm{E}+03$ & 0.146 & 0.055 & 1.053 & 0.505 & 1.519 & 0.65 & 7.8 & 89.2 & 4.268 & 0.464 \\
\hline PFC3-2 & 0.874 & 0.009 & 4.46 & 5.983 & 18.607 & 24.589 & $3.80 \mathrm{E}+03$ & 0.205 & 0.077 & 2.002 & 0.934 & 2.298 & 1.23 & 9 & 90.9 & 7.457 & 0.694 \\
\hline PFC3-4 & 0.83 & -0.171 & 2.811 & 3.824 & 3.711 & 7.535 & $4.39 \mathrm{E}+03$ & 0.122 & 0.101 & 0.759 & 0.625 & 2.271 & 0.799 & 7.9 & 90.3 & 5.832 & 0.673 \\
\hline PFC3-5 & 0.475 & 0.42 & 3.899 & 2.83 & 2.592 & 5.422 & $3.73 \mathrm{E}+03$ & 0.099 & 0.041 & 0.499 & 0.615 & 1.204 & 0.402 & 10.4 & 91.7 & 4.159 & 0.372 \\
\hline PFC3-6 & 0.625 & -0.067 & 2.914 & 2.9 & 2.846 & 5.746 & $3.20 \mathrm{E}+03$ & 0.11 & 0.047 & 0.605 & 0.546 & 1.678 & 0.606 & 8.6 & 90.6 & 4.579 & 0.502 \\
\hline \begin{tabular}{|l|} 
PFC3-8 \\
\end{tabular} & 0.383 & -0.293 & 3.379 & 1.823 & 2.161 & 3.984 & 3.67E+03 & 0.074 & 0.028 & 0.277 & 0.32 & 0.987 & 0.45 & 8.2 & 89.2 & 3.107 & 0.303 \\
\hline PFC3-9 & 0.888 & -0.241 & 4.427 & 5.497 & 5.151 & 10.648 & $3.58 \mathrm{E}+03$ & 0.134 & 0.054 & 0.879 & 1.02 & 2.033 & 1.131 & 8.6 & 86.5 & 8.424 & 0.678 \\
\hline PFC4-1 & 0.787 & 0.942 & 14.693 & 16.809 & 4.233 & 21.043 & $6.69 \mathrm{E}+03$ & 0.242 & 0.441 & 2.675 & 1.143 & 1.9 & 0.808 & 9.6 & 89.8 & 12.12 & 0.598 \\
\hline PFC4-2 & 0.652 & 0.088 & 3.528 & 5.564 & 4.76 & 10.323 & $6.19 \mathrm{E}+03$ & 0.207 & 0.186 & 2.111 & 0.777 & 1.63 & 0.713 & 10.6 & 90.7 & 5.669 & 0.511 \\
\hline PFC4-4 & 0.615 & -0.04 & 3.271 & 6.024 & 3.931 & 9.954 & $4.89 \mathrm{E}+03$ & 0.153 & 0.114 & 1.155 & 0.64 & 1.643 & 0.62 & 9.1 & 91.1 & 4.643 & 0.492 \\
\hline PFC4-5 & 0.496 & -0.127 & 5.597 & 9.148 & 7.866 & 17.014 & $4.91 \mathrm{E}+03$ & 0.13 & 0.097 & 0.831 & 0.651 & 1.223 & 0.682 & 9.1 & 88.9 & 4.556 & 0.385 \\
\hline PFC4-6 & 0.716 & 0.264 & 3.679 & 5.882 & 2.98 & 8.861 & $5.13 \mathrm{E}+03$ & 0.164 & 0.181 & 1.324 & 0.929 & 1.788 & 0.665 & 10.8 & 91.3 & 5.881 & 0.56 \\
\hline \begin{tabular}{|l|} 
PFC4-7 \\
\end{tabular} & 0.886 & -0.205 & 3.701 & 5.613 & 9.391 & 15.004 & $8.23 \mathrm{E}+03$ & 0.298 & 0.259 & 4.275 & 0.894 & 2.209 & 1.159 & 9.7 & 89.7 & 8.48 & 0.693 \\
\hline PFC4-8 & 0.591 & 0.073 & 3.224 & 3.812 & 2.967 & 6.779 & $4.71 \mathrm{E}+03$ & 0.135 & 0.111 & 0.903 & 0.617 & 1.551 & 0.577 & 9.6 & 91.1 & 4.876 & 0.47 \\
\hline \begin{tabular}{|l|} 
PFC4-9 \\
\end{tabular} & 0.654 & 0.056 & 3.433 & 5.526 & 3.574 & 9.099 & $4.72 \mathrm{E}+03$ & 0.17 & 0.155 & 1.425 & 0.754 & 1.631 & 0.685 & 10.5 & 89.8 & 5.28 & 0.514 \\
\hline PFC5-1 & 0.61 & -0.077 & 3.486 & 4.81 & 3.87 & 8.68 & $5.43 \mathrm{E}+03$ & 0.161 & 0.147 & 1.283 & 0.652 & 1.556 & 0.693 & 8.9 & 89.7 & 5.599 & 0.481 \\
\hline PFC5-2 & 1.28 & 2.852 & 27.639 & 19.253 & 6.953 & 26.206 & $5.80 \mathrm{E}+03$ & 0.39 & 0.335 & 6.118 & 2.231 & 2.6 & 1.131 & 9.8 & 89.9 & 20.657 & 0.862 \\
\hline PFC5-4 & 0.713 & -0.303 & 3.188 & 4.537 & 5.465 & 10.002 & $4.46 \mathrm{E}+03$ & 0.158 & 0.122 & 1.228 & 0.623 & 1.858 & 0.851 & 7.6 & 88.8 & 5.131 & 0.569 \\
\hline PFC5-5 & 0.551 & 0.072 & 3.384 & 3.096 & 4.369 & 7.465 & $5.09 \mathrm{E}+03$ & 0.143 & 0.122 & 1.009 & 0.601 & 1.418 & 0.586 & 9.7 & 90.7 & 4.589 & 0.435 \\
\hline PFC5-6 & 0.649 & 0.042 & 3.415 & 4.165 & 4.807 & 8.972 & $5.95 \mathrm{E}+03$ & 0.178 & 0.245 & 1.547 & 0.713 & 1.643 & 0.693 & 10.2 & 90.3 & 5.164 & 0.511 \\
\hline \begin{tabular}{|l|} 
PFC5-7 \\
\end{tabular} & 0.804 & -0.194 & 3.967 & 4.881 & 5.389 & 10.27 & $6.30 \mathrm{E}+03$ & 0.243 & 0.203 & 2.835 & 0.86 & 1.982 & 0.972 & 9.7 & 89.8 & 8.812 & 0.624 \\
\hline PFC5-8 & 0.532 & -0.067 & 3.695 & 4.631 & 4.096 & 8.727 & $4.87 \mathrm{E}+03$ & 0.14 & 0.116 & 0.974 & 0.584 & 1.326 & 0.626 & 9.8 & 89.5 & 4.314 & 0.417 \\
\hline PFC5-9 & 0.674 & 0.136 & 3.028 & 4.773 & 3.795 & 8.568 & $4.37 \mathrm{E}+03$ & 0.146 & 0.126 & 1.06 & 0.735 & 1.813 & 0.601 & 9.5 & 92 & 5.059 & 0.541 \\
\hline PFC6-1 & 0.714 & 0.161 & 3.094 & 4.044 & 3.039 & 7.084 & $5.46 \mathrm{E}+03$ & 0.146 & 0.156 & 1.054 & 0.786 & 1.873 & 0.595 & 9.5 & 90.7 & 5.258 & 0.569 \\
\hline \begin{tabular}{|l|} 
PFC6-2 \\
\end{tabular} & 0.747 & -0.068 & 3.775 & 6.582 & 19.075 & 25.657 & $6.18 \mathrm{E}+03$ & 0.24 & 0.202 & 2.76 & 0.808 & 1.935 & 1.191 & 9.7 & 90.8 & 6.75 & 0.592 \\
\hline \begin{tabular}{|l|} 
PFC6-4 \\
\end{tabular} & 0.53 & 0.261 & 3.374 & 5.296 & 3.025 & 8.321 & $4.30 \mathrm{E}+03$ & 0.114 & 0.096 & 0.64 & 0.646 & 1.373 & 0.49 & 11 & 92.2 & 3.912 & 0.421 \\
\hline PFC6-5 & 0.359 & 0.079 & 3.662 & 1.998 & 2.99 & 4.989 & $5.41 \mathrm{E}+03$ & 0.102 & 0.085 & 0.516 & 0.403 & 0.91 & 0.389 & 10.1 & 90.8 & 3.329 & 0.282 \\
\hline \begin{tabular}{|l|} 
PFC6-6 \\
\end{tabular} & 0.572 & -0.161 & 3.343 & 3.065 & 2.903 & 5.968 & $5.57 \mathrm{E}+03$ & 0.142 & 0.155 & 0.997 & 0.537 & 1.458 & 0.629 & 9.2 & 89.5 & 5.052 & 0.452 \\
\hline \begin{tabular}{|l|} 
PFC6-7 \\
\end{tabular} & 0.972 & -0.183 & 3.597 & 5.943 & 6.407 & 12.35 & $7.43 \mathrm{E}+03$ & 0.313 & 0.284 & 4.695 & 1.023 & 2.409 & 1.169 & 9.3 & 89.2 & 9.982 & 0.76 \\
\hline PFC6-8 & 0.646 & -0.673 & 3.811 & 3.355 & 3.719 & 7.074 & $4.66 \mathrm{E}+03$ & 0.126 & 0.082 & 0.794 & 0.453 & 1.508 & 0.947 & 6.9 & 85.5 & 5.388 & 0.504 \\
\hline \begin{tabular}{|l|} 
PFC6-9 \\
\end{tabular} & 0.641 & 0.081 & 3.428 & 5.157 & 5.619 & 10.776 & $5.52 \mathrm{E}+03$ & 0.151 & 0.184 & 1.123 & 0.726 & 1.633 & 0.69 & 10.2 & 90.4 & 5.571 & 0.506 \\
\hline PFC7-1 & 1.491 & -0.233 & 2.963 & 4.342 & 4.275 & 8.617 & $3.52 \mathrm{E}+03$ & 0.113 & 0.088 & 0.646 & 1.278 & 3.438 & 2.085 & 12.5 & 88.1 & 8.248 & 1.163 \\
\hline \begin{tabular}{|l|} 
PFC7-2 \\
\end{tabular} & 0.582 & -0.16 & 3.151 & 2.342 & 3.197 & 5.539 & $5.22 \mathrm{E}+03$ & 0.126 & 0.104 & 0.81 & 0.522 & 1.49 & 0.665 & 9.3 & 89.6 & 4.549 & 0.461 \\
\hline PFC7-4 & 0.752 & 0.336 & 3.175 & 3.89 & 3.175 & 7.065 & $4.34 \mathrm{E}+03$ & 0.137 & 0.113 & 0.931 & 0.823 & 2.018 & 0.566 & 10.5 & 93.1 & 6.008 & 0.604 \\
\hline PFC7-5 & 0.48 & 0.156 & 4.252 & 5.794 & 4.302 & 10.097 & $5.47 E+03$ & 0.123 & 0.101 & 0.754 & 0.634 & 1.183 & 0.555 & 10.7 & 91.2 & 4.89 & 0.373 \\
\hline PFC7-6 & 0.571 & 0.654 & 12.156 & 10.7 & 2.66 & 13.36 & $4.79 E+03$ & 0.145 & 0.11 & 0.99 & 0.785 & 1.408 & 0.591 & 9.6 & 89.9 & 8.23 & 0.439 \\
\hline PFC7-7 & 1.039 & 0.834 & 5.056 & 7.321 & 4.283 & 11.605 & 4.16E+03 & 0.169 & 0.132 & 1.444 & 1.908 & 2.173 & 0.98 & 12.9 & 90.6 & 8.703 & 0.764 \\
\hline PFC7-8 & 0.496 & -0.172 & 3.447 & 2.617 & 2.428 & 5.045 & $4.66 \mathrm{E}+03$ & 0.107 & 0.08 & 0.576 & 0.48 & 1.25 & 0.567 & 9.6 & 89.8 & 4.118 & 0.389 \\
\hline FC7-9 & 0.928 & -0.266 & 2.857 & 3.1 & 3.88 & 6.98 & $4.24 \mathrm{E}+03$ & 0.124 & 0.096 & 0.774 & 0.682 & 2.446 & 1.04 & 7.9 & 89.1 & 5.867 & 0.746 \\
\hline
\end{tabular}




\section{1}

2

3

\begin{tabular}{|c|c|c|c|c|c|c|c|c|c|c|c|c|c|c|c|c|c|}
\hline OLY031-1 & 349 & 0.113 & 2.593 & 4.502 & 5.163 & 9.665 & $2.32 \mathrm{E}+03$ & 0.113 & 0.039 & 0.637 & 0.961 & 3.772 & 1.228 & 7.2 & 90.3 & 8.003 & 1.099 \\
\hline POLY031-2 & 0.699 & -1.524 & 16.33 & 3.452 & 9.922 & 13.374 & $4.84 \mathrm{E}+03$ & 0.189 & 0.078 & 1.744 & 0.66 & 1.527 & 1.096 & 9.8 & 88.5 & 8.968 & 0.508 \\
\hline OLY031-4 & 0.689 & 0.122 & 3.314 & 3.53 & 4.261 & 7.792 & $3.26 \mathrm{E}+03$ & 0.144 & 0.051 & 1.03 & 0.78 & 1.734 & 0.714 & 10.9 & 91 & 5.202 & 0.543 \\
\hline OLY031-5 & .667 & -9.701 & 145.949 & 2.058 & 14.298 & 16.356 & $4.32 \mathrm{E}+03$ & 0.121 & .039 & 0.671 & 0.432 & 0.876 & 1.195 & 10.7 & 90.5 & 7.143 & 0.313 \\
\hline POLY031-6 & 1.344 & 0.767 & 3.105 & 5.211 & 4.013 & 9.224 & $2.34 \mathrm{E}+03$ & 0.123 & 0.055 & 0.75 & 2.448 & 2.344 & 0.934 & 22.3 & 90 & 7.877 & 1.047 \\
\hline POLY031-7 & 0.867 & -0.074 & 10.699 & 17.151 & 6.128 & 23.279 & $4.81 \mathrm{E}+03$ & 0.254 & 0.102 & 3.096 & 1.194 & 1.95 & 1.283 & 9.9 & 88.5 & 9.023 & 0.647 \\
\hline POLY031-8 & 0.525 & -0.349 & 4.791 & 2.879 & 3.34 & 6.219 & $3.49 \mathrm{E}+03$ & 0.112 & 0.038 & 0.618 & 0.546 & 1.199 & 0.751 & 11.1 & 89.6 & 5.422 & 0.397 \\
\hline POLY031-9 & 0.777 & 0.926 & 4.272 & 3.687 & 3.441 & 7.128 & $2.81 \mathrm{E}+03$ & 0.126 & 0.052 & 0.791 & 1.381 & 1.48 & 0.64 & 18.3 & 92 & 5.999 & 0.588 \\
\hline POLY040-1 & 0.653 & -0.439 & 3.798 & 2.877 & 3.523 & 6.4 & $3.63 \mathrm{E}+03$ & 0.134 & 0.048 & 0.894 & 0.567 & 1.608 & 0.874 & 8.3 & 88.7 & 5.189 & 0.508 \\
\hline POLY040-2 & 0.498 & 0.009 & 4.372 & 4.013 & 2.854 & 6.867 & $3.98 \mathrm{E}+03$ & 0.132 & 0.052 & 0.885 & 0.588 & 1.186 & 0.595 & 10.3 & 89.5 & 4.992 & 0.383 \\
\hline POLY040-3 & 1.273 & -0.935 & 4.963 & 4.932 & 6.26 & 11.192 & $3.35 \mathrm{E}+03$ & 0.15 & 0.052 & 1.105 & 1.272 & 2.118 & 2.689 & 15 & 85.4 & 9.196 & 0.895 \\
\hline \begin{tabular}{|l|} 
POLY040-4 \\
\end{tabular} & 0.653 & -0.257 & 3.335 & 3.286 & 4.494 & 7.78 & $3.85 \mathrm{E}+03$ & 0.168 & 0.066 & 1.405 & 0.588 & 1.657 & 0.804 & 7.8 & 88.5 & 5.441 & 0.516 \\
\hline OLY040-5 & 0.571 & -0.504 & 3.76 & 2.565 & 3.694 & 6.259 & $3.95 \mathrm{E}+03$ & 0.152 & 0.053 & 1.144 & 0.456 & 1.39 & 0.774 & 7.1 & 87 & 5.139 & 0.447 \\
\hline POLY040-6 & 0.433 & -0.469 & 4.544 & 2.854 & 2.715 & 5.568 & $4.06 \mathrm{E}+03$ & 0.113 & 0.039 & 0.637 & 0.435 & 0.999 & 0.628 & 9.1 & 88.1 & 4.259 & 0.329 \\
\hline POLY040-7 & 0.432 & -0.065 & 4.038 & 2.507 & 2.628 & 5.135 & $4.30 \mathrm{E}+03$ & 0.12 & 0.05 & 0.728 & 0.485 & 1.048 & 0.515 & 10.5 & 90.2 & 4.395 & 0.334 \\
\hline POLY040-8 & 0.636 & -0.439 & 4.251 & 5.706 & 4.892 & 10.598 & $3.99 \mathrm{E}+03$ & 0.156 & 0.071 & 1.211 & 0.61 & 1.597 & 0.837 & 8.3 & 89.3 & 5.762 & 0.497 \\
\hline POLY040-9 & 0.496 & -0.048 & 4.372 & 4.613 & 3.052 & 7.665 & $3.81 \mathrm{E}+03$ & 0.126 & 0.046 & 0.787 & 0.532 & 1.245 & 0.56 & 8.1 & 88.4 & 4.648 & 0.39 \\
\hline \begin{tabular}{|l|} 
POLY040-10 \\
\end{tabular} & 0.485 & -0.133 & 3.412 & 2.507 & 2.695 & 5.202 & $4.16 \mathrm{E}+03$ & 0.136 & 0.055 & 0.914 & 0.49 & 1.211 & 0.551 & 9.2 & 89.1 & 4.104 & 0.38 \\
\hline \begin{tabular}{|l|} 
Poly041-1 \\
\end{tabular} & 0.757 & 1.216 & 10.797 & 5.89 & 2.667 & 8.557 & $3.37 \mathrm{E}+03$ & 0.107 & 0.042 & 0.572 & 1.353 & 1.381 & 1.006 & 10 & 87 & 7.895 & 0.512 \\
\hline Poly041-2 & 1.697 & -0.924 & 6.35 & 12.417 & 10.81 & 23.226 & $2.77 \mathrm{E}+03$ & 0.221 & 0.049 & 2.089 & 2.225 & 3.033 & 2.954 & 12.4 & 85.3 & 12.623 & 1.203 \\
\hline Ooly041-3 & 0.255 & -0.28 & 7.679 & 4.082 & 2.751 & 6.833 & $4.77 \mathrm{E}+03$ & 0.077 & 0.034 & 0.306 & 0.335 & 0.602 & 0.334 & 10.1 & 89.5 & 2.762 & 0.194 \\
\hline Poly041-4 & 0.501 & -0.137 & 4.16 & 3.79 & 2.694 & 6.484 & $3.89 E+03$ & 0.134 & 0.053 & 0.89 & 0.596 & 1.183 & 0.644 & 9.5 & 88.8 & 4.582 & 0.384 \\
\hline Poly041-5 & 0.581 & -0.272 & 7.135 & 3.543 & 5.371 & 8.914 & $3.74 \mathrm{E}+03$ & 0.126 & 0.048 & 0.786 & 0.751 & 1.287 & 0.761 & 10 & 88.9 & 5.972 & 0.428 \\
\hline \begin{tabular}{|l} 
Poly041-6 \\
\end{tabular} & 1.032 & -0.094 & 3.468 & 3.846 & 5.721 & 9.567 & $2.86 \mathrm{E}+03$ & 0.114 & 0.042 & 0.649 & 1.035 & 2.441 & 1.262 & 12.1 & 89.1 & 7.478 & 0.801 \\
\hline Poly041-7 & 1.04 & 1.474 & 5.308 & 4.954 & 5.982 & 10.936 & 2.10E+03 & 0.104 & 0.042 & 0.535 & 2.291 & 1.564 & 0.664 & 21.7 & 94.7 & 7.981 & 0.77 \\
\hline \begin{tabular}{|l} 
Poly041-8 \\
\end{tabular} & 0.924 & -1.146 & 6.29 & 2.979 & 6.552 & 9.531 & $3.36 \mathrm{E}+03$ & 0.137 & 0.047 & 0.935 & 0.72 & 1.898 & 1.81 & 10.1 & 87.9 & 7.542 & 0.668 \\
\hline Poly041-9 & 0.504 & -0.125 & 4.47 & 3.933 & 2.59 & 6.523 & $3.95 \mathrm{E}+03$ & 0.129 & 0.05 & 0.831 & 0.502 & 1.224 & 0.619 & 8.8 & 88.3 & 4.339 & 0.391 \\
\hline \begin{tabular}{|l|} 
Poly041-10 \\
\end{tabular} & 0.598 & -0.42 & 3.843 & 2.75 & 4.971 & 7.721 & $4.06 \mathrm{E}+03$ & 0.136 & 0.054 & 0.929 & 0.481 & 1.491 & 0.765 & 8 & 87.9 & 5.426 & 0.4 \\
\hline POLY042-2 & 0.685 & -2.336 & 31.095 & 2.726 & 10.715 & 13.441 & $3.73 E+03$ & 0.133 & 0.046 & 0.841 & 0.685 & 1.461 & 1.026 & 10.1 & 89.4 & 9.551 & 0.483 \\
\hline POLY042-3 & 0.521 & 0.146 & 3.622 & 3.878 & 4.227 & 8.105 & $3.93 \mathrm{E}+03$ & 0.106 & 0.048 & 0.555 & 0.617 & 1.337 & 0.561 & 10 & 91.3 & 4.696 & 0.41 \\
\hline POLY042-4 & 0.334 & -1.327 & 7.736 & 1.789 & 2.889 & \begin{tabular}{|l|l|}
4.677 \\
\end{tabular} & $3.92 \mathrm{E}+03$ & 0.083 & 0.026 & 0.344 & 0.267 & 0.689 & 0.602 & 8.3 & 86.4 & 3.651 & 0.242 \\
\hline POLY042-5 & 0.507 & -0.836 & 9.329 & 5.361 & 8.664 & 14.025 & $3.71 E+03$ & 0.118 & 0.039 & 0.682 & 0.654 & 1.023 & 0.888 & 9.4 & 86.8 & 5.981 & 0.362 \\
\hline POLY042-6 & 0.625 & -0.709 & 12.274 & 3.68 & 7.582 & 11.262 & $3.94 \mathrm{E}+03$ & 0.156 & 0.071 & 1.182 & 0.781 & 1.401 & 0.783 & 12.1 & 90.9 & 8.886 & 0.463 \\
\hline POLY042-7 & 0.556 & -0.005 & 4.304 & 7.003 & 3.543 & 10.546 & $3.63 \mathrm{E}+03$ & 0.12 & 0.043 & 0.709 & 0.697 & 1.393 & 0.641 & 9.4 & 90.3 & 5.62 & 0.433 \\
\hline POLY042-8 & 0.7 & -0.167 & 3.356 & 3.018 & 7.544 & 10.561 & $3.90 \mathrm{E}+03$ & 0.172 & 0.063 & 1.461 & 0.59 & 1.875 & 0.8 & 8.6 & 90.7 & 5.855 & 0.561 \\
\hline POLY042-9 & 0.637 & -0.298 & 2.807 & 3.079 & 4.311 & 7.391 & $3.59 \mathrm{E}+03$ & 0.156 & 0.051 & 1.206 & 0.421 & 1.745 & 0.69 & 6.7 & 89.5 & 4.243 & 0.516 \\
\hline POLY042-10 & 1.254 & 0.42 & 3.706 & 7.136 & 10.563 & 17.699 & $2.85 \mathrm{E}+03$ & 0.123 & 0.04 & 0.638 & 1.658 & 2.949 & 1.1 & 12.1 & 88.6 & 7.937 & 0.973 \\
\hline POLY049-1 & 0.641 & -0.425 & 3.138 & 3.122 & 2.847 & 5.969 & $3.98 \mathrm{E}+03$ & 0.158 & 0.055 & 1.239 & 0.47 & 1.675 & 0.759 & 6.3 & 88.3 & 4.661 & 0.515 \\
\hline POLY049-2 & 0.277 & -0.019 & 4.616 & 1.878 & 2.205 & 4.083 & $4.31 \mathrm{E}+03$ & 0.077 & 0.03 & 0.296 & 0.321 & 0.66 & 0.351 & 9.2 & 88.8 & 2.875 & 0.212 \\
\hline POLY049-3 & 0.438 & -0.148 & 5.218 & 3.71 & 4.598 & 8.308 & $4.51 \mathrm{E}+03$ & 0.122 & 0.052 & 0.762 & 0.532 & 1.013 & 0.641 & 10.4 & 90.1 & 4.225 & 0.33 \\
\hline POLY049-4 & 0.558 & -0.382 & 4.226 & 2.466 & 3.344 & 5.81 & $4.12 \mathrm{E}+03$ & 0.149 & 0.053 & 1.099 & 0.549 & 1.338 & 0.727 & 8.3 & 88.1 & 5.357 & 0.431 \\
\hline POLY049-5 & 0.543 & -0.554 & 4.605 & 4.696 & 4.375 & 9.071 & $3.78 \mathrm{E}+03$ & 0.129 & 0.046 & 0.827 & 0.546 & 1.26 & 0.801 & 9.5 & 87.9 & 6.013 & 0.415 \\
\hline POLY049-6 & 0.357 & -0.384 & 4.791 & 2.213 & 3.009 & 5.223 & $4.28 \mathrm{E}+03$ & 0.099 & 0.039 & 0.497 & 0.386 & 0.796 & 0.53 & 9.6 & 87.5 & 3.666 & 0.268 \\
\hline POLY049-7 & 0.518 & -0.057 & 4.578 & 4.337 & 3.38 & 7.718 & $4.84 \mathrm{E}+03$ & 0.16 & 0.075 & 1.269 & 0.619 & 1.198 & 0.654 & 10.1 & 88.3 & 6.213 & 0.395 \\
\hline POLY049-8 & 0.634 & -8.27E-04 & 3.717 & 3.93 & 4.058 & 7.988 & $3.93 \mathrm{E}+03$ & 0.167 & 0.071 & 1.385 & 0.708 & 1.563 & 0.711 & 9.8 & 89.4 & 5.809 & 0.494 \\
\hline POLY049-9 & 0.451 & -0.772 & 5.66 & 2.335 & 3.088 & 5.422 & $4.02 \mathrm{E}+03$ & 0.112 & 0.043 & 0.62 & 0.431 & 0.983 & 0.727 & 9.2 & 87.5 & 4.717 & 0.334 \\
\hline POLY049-10 & 0.509 & -0.349 & 3.588 & 2.725 & 2.697 & 5.422 & $4.58 \mathrm{E}+03$ & 0.151 & 0.062 & 1.127 & 0.455 & 1.243 & 0.647 & 8.5 & 87.9 & 4.543 & 0.398 \\
\hline
\end{tabular}

